\title{
An audit of clinical service examining the uptake of genetic testing by at-risk family members
}

\author{
Laura Forrest, Grad Dip Gen Couns, PhD ${ }^{1-4}$, Martin Delatycki, MBBS, PhD ${ }^{3-5}$, Lisette Curnow, \\ M. Gen Couns ${ }^{6}$, Loane Skene, LLD, LLB (Hons) ${ }^{7}$ and MaryAnne Aitken, Grad Dip Gen Couns, PhD ${ }^{1,4}$
}

Purpose: The aim of this study was to investigate the uptake of genetic testing by at-risk family members for four genetic conditions: chromosomal translocations, fragile $\mathrm{X}$ syndrome, Huntington disease, and spinal muscular atrophy.

Methods: A clinical audit was undertaken using genetics files from Genetic Health Services Victoria. Data were extracted from the files regarding the number of at-risk family members and the proportion tested. Information was also collected about whether discussion of atrisk family members and family communication during the genetic consultation was recorded.

Results: The proportion of at-risk family members who had genetic testing ranged from $11 \%$ to $18 \%$. First-degree family members were most frequently tested and the proportion of testing decreased by degree of relatedness to the proband. Smaller families were significantly more likely to have genetic testing for all conditions except Huntington disease. Female at-risk family members were significantly more likely to have testing for fragile $\mathrm{X}$ syndrome.

Conclusion: The majority of at-risk family members do not have genetic testing. Family communication is likely to influence the uptake of genetic testing by at-risk family members and therefore it is important that families are supported while communicating to ensure that at-risk family members are able to make informed decisions about genetic testing.

Genet Med 2012:14(1):122-128

Key Words: at-risk family members; clinical audit; family communication; genetic testing; noncancer genetic conditions

\section{INTRODUCTION}

The importance of communicating genetic information in families is based on the premise that family members have a right to make an informed decision about their risk. If family members know that they are at risk, then they may either have genetic testing or choose not to have genetic testing. One way of knowing that communication has been successful is if at-risk family members contact genetic services for genetic counseling or testing. However, if family members decide not to contact genetic services or have genetic testing, then the success of family communication cannot be confirmed.

Family communication plays a significant role in educating and informing at-risk family members about the familial genetic condition. During the communication of genetic information consultands experience many barriers and facilitators ${ }^{1}$ that impact the outcome of communication and affect the understanding of at-risk family members. Even family members who have been told about the genetic condition may not be cognizant of the personal ramifications or of the availability of genetic testing. This situation was experienced by participants in a research study about family communication who were first-degree family members at risk of carrying a familial BRCA mutation. ${ }^{2}$ Once informed of the health and reproductive implications of hereditary breast and ovarian cancer and the availability of genetic testing, all the participants opted to be tested for their familial BRCA mutation. ${ }^{2}$ This study highlighted the difficulties involved with family communication, where even the closest relations are often not adequately informed of their risk. The interest and subsequent uptake of genetic testing by all of these first-degree family members indicates that an understanding of personal risk may lead to the decision to have testing.

At-risk family members' decisions about genetic testing are also likely to be influenced by the health and reproductive implications of the genetic condition and the availability of prevention or treatment. For example, the uptake of predictive testing by asymptomatic family members who are at risk of developing Huntington disease (HD) has been lower than expected since the genetic basis of HD was determined in 1993. ${ }^{3,4}$ The lack of treatment that could prevent or halt the inexorable decline caused by HD means that many at-risk family members choose not to have predictive testing and rationalize this decision through an inability to cope with a positive test result or a tolerance for living with uncertainty. ${ }^{5,6}$ In contrast, although the uptake of genetic testing is still reported at low proportions, ${ }^{7}$ decisions about testing by family members at

${ }^{1}$ Genetics Education and Health Research, Murdoch Childrens Research Institute, Royal Children's Hospital, Parkville, Australia; ${ }^{2}$ Australian Primary Health Care Research Institute, Australian National University, Canberra, Australia; ${ }^{3}$ Bruce Lefroy Centre for Genetic Health Research, Murdoch Childrens Research Institute, Royal Children's Hospital, Parkville, Australia; ${ }^{4}$ Department of Paediatrics, The University of Melbourne, Melbourne, Australia; ${ }^{5}$ Clinical Genetics, Austin Health, Heidelberg, Australia; ${ }^{6}$ Genetic Health Services Victoria, Royal Children's Hospital, Parkville, Australia; ${ }^{7}$ The Melbourne Law School, The University of Melbourne, Melbourne, Australia. Correspondence: Laura Forrest (laura.forrest@anu.edu.au) 
risk of inheriting a familial cancer syndrome are influenced by being able to prepare for a future that includes the availability of treatment. ${ }^{8}$ Furthermore, it is possible that some at-risk family members receive genetic information and understand the personal health and reproductive implications but decide not to pursue genetic testing because they do not want to know their genetic status or have no reproductive intentions.

Although the uptake of testing may only be an indication of the minimum proportion of family members who are informed, it provides a minimum basis to determine the frequency that family communication occurs in families. There have been very few studies investigating the proportion of at-risk family members who have genetic testing for noncancer genetic conditions and the link with family communication. Therefore, the aim of this study was to investigate the uptake of genetic testing by atrisk family members for noncancer genetic conditions including chromosomal translocations, fragile X syndrome (FXS), $\mathrm{HD}$, and spinal muscular atrophy type I (SMA).

\section{METHODS}

A clinical audit was undertaken using the information contained in genetic files from Genetic Health Services Victoria (GHSV) and laboratory reports from Victorian Clinical Genetics Services laboratories (VCGS). These genetic files are a subset of medical records and are stored securely by GHSV, where each file contains the details of one family's genetic care rather than just one individual in that family. The organization of the genetics service in the state of Victoria, Australia, was, at the time of the audit, a centralized service; therefore, all Victorian families' genetics files were located at GHSV. The files include a family pedigree and document the content of the genetic consultations and laboratory reports produced by VCGS detailing the results of genetic testing of probands and their family members.

\section{Ethics Committee approval}

The Royal Children's Hospital Human Research Ethics Committee approved this clinical audit (ref no. CA27032).

\section{Genetic conditions}

Four genetic conditions were chosen for inclusion: chromosomal translocation, FXS, HD, and SMA. These conditions were chosen to represent four types of inheritance with varied health and reproductive implications for the proband, obligate carriers, and at-risk family members (see Supplementary Table S1). In addition, these conditions were chosen because VCGS offers the only laboratory testing for SMA, HD, and FXS in Victoria. Other private laboratories in Victoria also offer karyotyping, which introduced a limitation to the data collection for chromosomal translocations.

\section{Data collection}

In December 2007, the GHSV electronic database was interrogated for probands who were diagnosed after genetic testing by the VCGS laboratories confirmed one of the four conditions between 1 January 2000 and 31 December 2004. The genetics
Table 1 Details about probands and at-risk family members collected from the genetics files

\begin{tabular}{|c|c|}
\hline Proband & Family members \\
\hline Name & Name \\
\hline Date of birth & Date of birth \\
\hline Date of diagnosis & Relationship to proband \\
\hline Mutation details & Risk of being a carrier \\
\hline $\begin{array}{l}\text { Whether file notes document } \\
\text { discussion about family } \\
\text { communication }\end{array}$ & $\begin{array}{l}\text { Maternal or paternal side of the } \\
\text { proband's family }\end{array}$ \\
\hline $\begin{array}{l}\text { Whether summary letter sent } \\
\text { postconsultation mentioned } \\
\text { family communication }\end{array}$ & $\begin{array}{l}\text { Whether the family member had } \\
\text { genetic testing for the genetic } \\
\text { condition affecting the proband }\end{array}$ \\
\hline \multirow[t]{2}{*}{$\begin{array}{l}\text { Whether there was a letter written } \\
\text { specifically for family members }\end{array}$} & $\begin{array}{l}\text { If the family members had genetic } \\
\text { testing, the date of the genetic } \\
\text { test }\end{array}$ \\
\hline & $\begin{array}{l}\text { Whether family members had } \\
\text { their genetic status clarified by the } \\
\text { test result of another relative }\end{array}$ \\
\hline
\end{tabular}

files retrieved from the electronic search were manually examined and information from the family pedigree and file notes were entered into a Microsoft Access database. Information collected from the genetics files is documented in Table 1. The family members' clarification of genetic status was included to capture those family members whose genetic status was clarified without testing as a result of their at-risk parent testing negative.

\section{Inclusion criteria}

Family members were included in this audit if their genetic risk of carrying or developing the genetic condition was up to $1 / 8$, they were more than 18 years of age, or they were less than 18 years of age but had genetic testing for FXS or SMA due to developmental concerns.

\section{Exclusion criteria}

Family members were excluded from the clinical audit if there was documentation indicating that they were less than 18 years of age and their genetic status was not clarified or they did not reside in Victoria, Australia.

\section{Data analysis}

Numbers and percentages were used to summarize the documentation included in the genetic files regarding discussion of at-risk family members and inclusion of letters. The usual method for assigning confidence intervals (CIs) to the raw percentage was not used here because it assumes that the data are independent and does not allow for the fact that the uptake of genetic testing could be correlated within families. One family member's decision to undergo testing is likely to influence the decision of other family members and, therefore, their decisions are more likely to be the same. The resulting CIs from this analysis would be too narrow because they do not allow for the correlation of uptake of testing within families. 
To allow for the familial correlation (or "clustering") on genetic testing uptake, the regression-based method of marginal models fitted using generalized estimating equations (GEEs) with information-sandwich estimates of standard error was used to estimate adjusted uptake percentages and 95\% CIs. ${ }^{9}$ The GEE method accounts for clustering using a weighted estimating equations approach. Both the CIs and the estimated percentage of uptake are adjusted for familial clustering and will differ from the simple analysis.

The raw unadjusted percentage has the disadvantage for these data that larger families may have a disproportionately large influence on the estimated percentage. For example, if most members in the larger families have had testing but testing levels are low in the smaller families, this will inflate the estimated percentage of testing. The GEE method allows for this because the estimated percentage is adjusted for clustering. The unadjusted percentage is also presented here, however, and still remains of interest as a means of quantifying the uptake in the sample.

The GEE method was used to investigate whether there was any association between the provision of letters for the consultand to distribute to family members and the uptake of genetic testing. This regression-based method of GEE used the uptake of testing as the outcome and the provision of a letter as the only predictor in the model.

Linear regression was used for each condition to determine whether family members with a higher risk were more likely to have genetic testing sooner after the proband was diagnosed as compared with family members with a lower risk. This regression-based method estimated the mean difference between each risk category $(1 / 2,1 / 4$, and $1 / 8)$ and the reference category (a risk of 1) with respect to the time taken for uptake of the genetic test among those who had taken the test. To adjust the standard errors and overall $P$ value for clustering within families, random-effects linear regression estimated using maximum likelihood was used. ${ }^{10}$

To investigate whether there was any correlation between the size of the proband's family and the uptake of genetic testing by family members, an overall raw percentage was reported for families with 20 members or fewer and families with more than 20 family members, as well as for each condition. The GEE model was then used to determine whether there was any association between family size and the uptake of testing by providing an adjusted percentage and 95\% CI of the difference between the two categories of family size, which allows for clustering. A $P$ value $<0.05$ was considered statistically significant.

\section{Nonidentifiable family members}

The results presented are inclusive of all family members represented on the pedigree according to the inclusion criteria. Many of these family members were represented only as a symbol and lacked enough identifying information to determine whether they had had genetic testing. Sixty and $65 \%$ of at-risk family members were nonidentifiable for chromosomal translocation and SMA, respectively. In comparison, $32 \%$ and $36 \%$ of family members were nonidentifiable for HD and FXS, respectively.

\section{Descriptions of genetics files}

\section{RESULTS}

Seventy-four probands diagnosed with one of the four conditions and 1,213 at-risk family members were identified from the 5-year period between 1 January 2000 and 31 December 2004. A total of 32 probands were diagnosed with a chromosomal translocation, resulting in 495 at-risk family members; 16 were diagnosed with FXS, resulting in 264 at-risk family members; 14 were diagnosed with HD, resulting in 164 at-risk family members; , and 12 were diagnosed with SMA, resulting in 290 at-risk family members.

\section{Documentation regarding at-risk family members in the genetic files}

Approximately half (chromosomal translocation 50\%; FXS 44\%; HD 57\%; SMA 42\%) of the genetic files included notes documenting that discussion had occurred with the probands or with their parents (the consultands), in the case of probands who were minors, about their at-risk family members. The majority of genetics files contained a copy of a summary letter sent to the probands their parents after their consultation, except for probands who had been diagnosed with HD (see Table 2).

\section{Genetic testing in family members}

The overall proportion of at-risk family members who had genetic testing was $16.2 \%$; however, when cluster analysis was used, this percentage increased to $19.8 \%$. The adjusted

Table 2 The documentation included in the genetics files

\begin{tabular}{|c|c|c|c|c|}
\hline & $\begin{array}{l}\text { Chromosomal } \\
\text { translocation } \\
\end{array}$ & $\begin{array}{c}\text { Fragile } X \\
\text { syndrome } \\
\end{array}$ & $\begin{array}{c}\text { Huntington } \\
\text { disease }\end{array}$ & $\begin{array}{c}\text { Spinal muscular } \\
\text { atrophy }\end{array}$ \\
\hline Discussion about at-risk family members documented in genetic file? & $16(50)$ & $7(44)$ & $8(57)$ & $5(42)$ \\
\hline Summary letter sent after a consultation? & $30(94)$ & $15(94)$ & $6(43)^{a}$ & $10(83)$ \\
\hline $\begin{array}{l}\text { If letter was sent to proband after consultation, were at-risk family members } \\
\text { mentioned? }\end{array}$ & $22 / 30(73)$ & $6 / 15(40)$ & $6 / 6(100)$ & $5 / 10(50)$ \\
\hline
\end{tabular}

an the Huntington disease files, the small percentage of summary letters reflects the mode of care in place in the state of Victoria, whereby letters are rarely written for the consultand undergoing predictive testing to pass on to family members. 
proportion of at-risk family members who were tested was 24.9\% (95\% CI 17.2 to 32.7) for a chromosomal translocation, $17.8 \%$ (95\% CI 10.8 to 24.7 ) for FXS, $17.4 \%$ (95\% CI 10.7 to 24.0 ) for $\mathrm{HD}$, and $10.8 \%$ (95\% CI 8.3 to 13.4 ) for SMA.

There was no association between the provision of a letter for the consultand to pass on to family members and the uptake of genetic testing by family members for chromosomal translocations $(P=0.8)$, FXS $(P=0.6)$, or SMA $(P=0.2)$. No letters were provided to consultands diagnosed with $\mathrm{HD}$.

The uptake of testing has been categorized according to whether the family members were first-degree, second-degree, third-degree, or more distant relatives of the proband. The firstdegree family members, parents, siblings, and children, have the highest uptake of genetic testing for all the conditions (see Table 3).

\section{Time between diagnosis and testing in at-risk family} members

Family members had testing over a range of time beginning within days of the proband's diagnosis to almost 7 years or 2,530 days later. The average time of testing ranged from 295 days for FXS to 317 days for HD, 378 days for SMA, and 440 days for a chromosomal translocation. The number of family members who chose to have testing declined over time, with $54 \%$ tested within the first 6 months after the proband had been diagnosed. Of those family members who had genetic testing,
84\% did so within 18 months after the proband's diagnosis (see Supplementary Figure S1).

Overall, there was an association between family members' risk and the time taken to have testing after the proband was diagnosed $(P=0.02)$. However, when the data were analyzed according to condition, family members with a higher risk of carrying a chromosomal translocation were significantly more likely to have testing sooner after the proband's diagnosis than those with a lower risk $(P=0.02)$. Similarly, family members at higher risk of carrying FXS had testing sooner than those at lower risk $(P=0.04)$. However, there was no association between risk and the time taken until testing for family members at risk of $\mathrm{HD}(P=0.4)$ or carrying SMA $(P=0.7)$.

\section{Family size and impact on genetic testing}

The number of family members documented on the pedigree was used as an indication of the size of the proband's family. Family size has a significant effect on the number of at-risk family members who have genetic testing. Individuals in families composed of 20 members or fewer were significantly more likely to have genetic testing than those from families with more than 20 family members $(P<0.001)$. When considering each of the conditions separately, the same association was evident between family size and test uptake for a chromosomal translocation $(P<0.001)$, FXS $(P=0.001)$, and SMA $(P=0.03)$ (see Table 4$)$.

Table 3 Uptake of genetic testing of first- and second-degree family members, and third-degree and more distant relatives of the proband

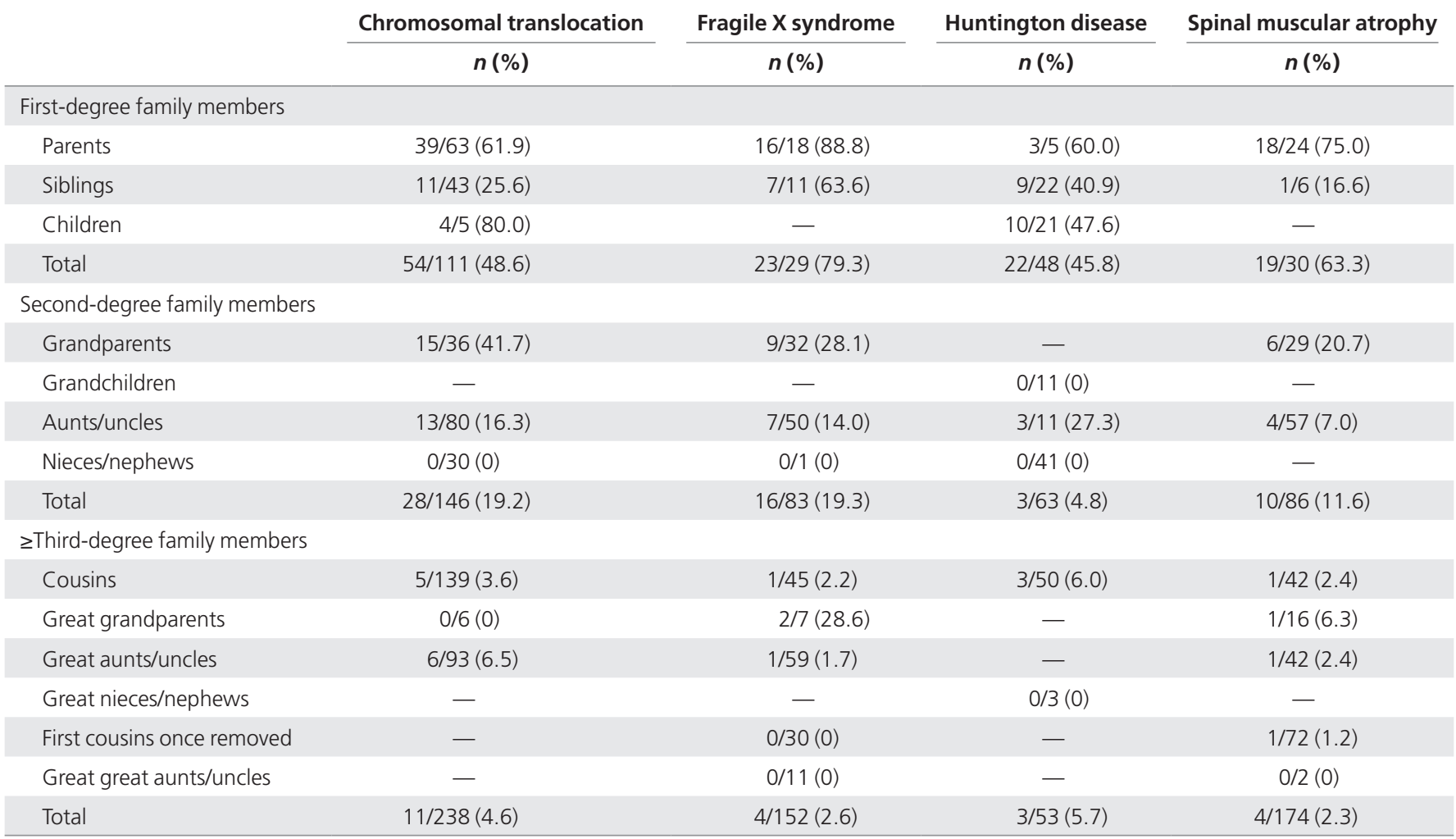




\section{Gender and testing}

There were no differences in the proportion of female and male family members who had genetic testing for $\operatorname{SMA}\left(\chi^{2}=0.2\right.$, $P=0.6)$, HD $\left(\chi^{2}=0.2, P=0.6\right)$, or chromosomal translocation $\left(\chi^{2}=1.2, P=0.3\right)$. However, a significantly greater number of female family members were tested for FXS (29.8\%) than male family members $\left(14.7 \% ; \chi^{2}=6.2, P=0.01\right)$.

\section{Clarification of genetic status in family members}

Many family members' genetic status was clarified from being at risk to not at risk after another relative tested negative for the familial mutation or translocation. None of these family members had genetic testing themselves (see Table 5).

\section{DISCUSSION}

This is the first study to examine and compare the uptake of genetic testing by at-risk family members for four noncancer genetic conditions of differing modes of inheritance and with different health implications for the tested individual. Overall, less than $20 \%$ of at-risk family members had genetic testing for $\mathrm{HD}, \mathrm{SMA}, \mathrm{FXS}$, and chromosomal translocations, resulting in more than $80 \%$ of at-risk family members remaining untested. When allowing for clustering, the overall proportion of tested family members increased slightly to $20 \%$ (95\% CI 15.8 to 23.9). Despite the minority of at-risk family members undergoing testing, this testing sometimes resulted in the clarification of other family members' genetic status. In the case of FXS, after familial clustering was accounted for, an estimated 43\% (95\%
CI 29.2 to 57.1) of family members had their genetic status clarified. In this study population, family members who were more closely related to the proband had higher rates of testing, and most testing occurred within 18 months of the proband's diagnosis. Documentation in the genetics files and summary letters written to probands regarding discussion about at-risk family members was variable.

There is limited information currently available about the frequency of genetic testing in at-risk family members for noncancer genetic conditions to compare with the results of this audit. A study by McClaren et al. ${ }^{11}$ conducted concurrently at GHSV with our research investigated the uptake of cystic fibrosis (CF) carrier testing by at-risk family members. This study determined that $16 \%$ of at-risk family members had carrier testing after the diagnosis of a child with CF through the Victorian newborn screening program. ${ }^{11}$ This proportion is comparable to the percentage of family members tested for FXS (18\%, 95\% CI 10.8 to 24.7), HD (17\%, 95\% CI 10.7 to 24.0$)$, and SMA (11\%, 95\% CI 8.3 to 13.4). The strength of the study by McClaren et al. ${ }^{11}$ lies in the confirmation of the probands' pedigrees by the probands' parents, ensuring accurate family histories inclusive of relatives whose risk of carrying CF is $1 / 8$ and therefore an accurate estimation of the proportion of family members tested for their CF carrier status. However, the consequence of using this method resulted in the inclusion of only 30 of the 82 (37\%) families whose children were diagnosed with CF between the 1 January 2000 and 31 December 2004. Therefore, 52 probands who were diagnosed with CF and their at-risk family members were not

Table 4 The effect of family size on the proportion of family members who have genetic testing

\begin{tabular}{|c|c|c|c|c|c|}
\hline & \multicolumn{2}{|c|}{ Number of family members (\% tested) } & \multirow[b]{2}{*}{ Fragile $X$ syndrome } & \multirow[b]{2}{*}{ Huntington disease } & \multirow[b]{2}{*}{$\begin{array}{c}\text { Spinal muscular } \\
\text { atrophy }\end{array}$} \\
\hline & Total & $\begin{array}{l}\text { Chromosomal } \\
\text { translocation }\end{array}$ & & & \\
\hline$>20$ family members & $632(8.7)$ & $243(8.2)$ & $102(6.9)$ & $44(11.2)$ & $243(9.5)$ \\
\hline $\begin{array}{l}\text { Difference tested, \% } \\
(95 \% \mathrm{CI})\end{array}$ & $15.7(11.6$ to 19.9$)$ & $20.7(14.2$ to 27.3$)$ & 15.4 (7.3 to 23.4$)$ & $7.8(-3.9$ to 19.5$)$ & $11.8(-0.1$ to 24.1$)$ \\
\hline
\end{tabular}

$\mathrm{Cl}$, confidence interval.

Table 5 The number of family members whose genetic status was clarified through personal genetic testing or indirectly through a family member's test result

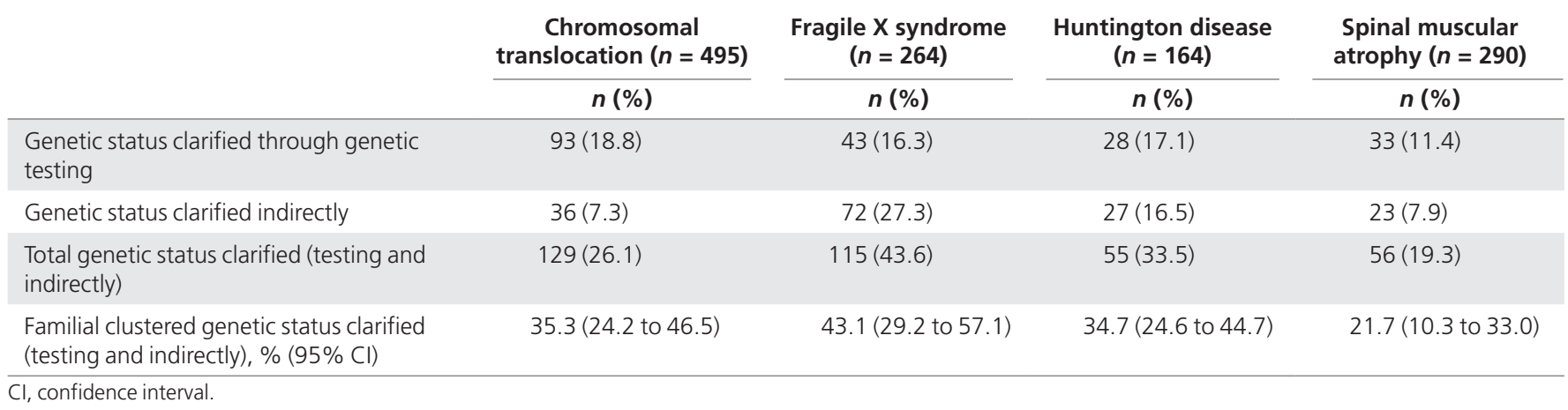


included in the calculation of the proportion of family members tested. In contrast, our study included every proband diagnosed in Victoria with a chromosomal translocation, FXS, HD, or SMA between the same dates but did not confirm the family pedigree with probands or consultands. Although the studies differ in their methodological approach to estimating the proportion of tested family members, they are unique in that the findings are not reliant on the probands' or consultands' recall and/or knowledge of who has had genetic testing in their families.

\section{Family communication and uptake of genetic testing}

Communicating genetic information to family members is likely to play an influential role in the uptake of genetic testing, where family members who are closer in relationship, in relatedness or emotionally, may be more likely to be informed about their risk, understand the implications of the genetic information, and choose to have genetic testing. A number of studies have examined the communication of noncancer genetic information to family members and the subsequent uptake of genetic testing. ${ }^{12,13}$ Van Rijn et al..$^{13}$ documented the number of at-risk family members who attended genetic counseling and had subsequent testing after 19 probands were diagnosed with FXS in a 4-year period between 1991 and 1995. The consultands reported informing all the probands' first-degree family members, but the proportion of second-, third-, and fourth-degree family members who were informed was progressively lower. ${ }^{13}$ The resulting percentage of at-risk family members who had testing was high for first-degree (90\%) and moderate for second-degree (37\%) but declined dramatically in third- and fourth-degree family members. This outcome is reflected in the findings of our study, in which first-degree family members are most frequently tested and the proportion of testing diminishes as the degree of relatedness declines, and in which the smaller families included in this study had a higher proportion of testing as compared with larger families. Other studies have also reported a decrease in the proportion of testing between second- and third-degree family members, which is linked to the reported decrease in communication of at-risk status to more distant relatives. ${ }^{14,15}$ Nevertheless, the proportion of family members who have genetic testing is not a perfect measure for family communication because it is possible that at-risk family members decline to have genetic testing because they do not want to know their genetic status or they have no reproductive intentions. However, the documented decrease in communication to second- and third-degree family members and the parallel decrease in the frequency of genetic testing suggests a link between family communication and genetic testing.

With regard to communication of genetic information and the preparation that consultands receive from genetic health professionals during a consultation, approximately half of the genetics files documented discussion about at-risk family members. These findings are in contrast with an international survey of genetic health professionals' practice that found that counseling consultands about at-risk family members and family communication occurred consistently during consultations. ${ }^{19}$ However, a lack of documentation in the genetics files does not mean that this discussion did not occur; it may have occurred and not been recorded. This may have significant ramifications if there is litigation by at-risk family members who are unaware of their genetic risk. Two cases in the United States involving plaintiffs suing their parents' physicians for failing to warn them of their genetic risk recorded different outcomes. ${ }^{20-23}$ In the case of Pate v. Threlkel, ${ }^{21}$ the Florida Supreme Court ruled that although the physician had a duty to warn of an inherited condition, this duty is fulfilled by warning the patient. In the subsequent case of Safer v. Estate of Pack, ${ }^{22}$ the Superior Court of New Jersey ruled that physicians should take reasonable steps to ensure that at-risk family members are warned of their risk. Consequently, if genetics files do not accurately record discussions about at-risk family members, genetic health professionals may increase their liability of litigation.

\section{Implications of genetic testing}

The implications inherent in genetic testing differ according to the condition. A marked difference between HD and the other three conditions is the predictive nature of genetic testing for HD for at-risk family members and the finality of the manifestation of HD later in life after a positive test result. Health and reproductive implications for carrier testing for FXS include that female premutation carriers are at risk of developing primary ovarian insufficiency and male and female premutation carriers are at risk of developing fragile $\mathrm{X}$-associated tremor/ ataxia syndrome..$^{24}$ In contrast, a positive carrier test result for SMA or a positive result for a chromosomal translocation does not change the individual's anticipated life course. However, the diagnosis of SMA in an infant is likely to have an impact on the family due to the onset of symptoms often being prior to 6 months of age, progressive muscular atrophy, and premature death in the vast majority. ${ }^{25}$ The very low percentage of testing in family members at risk of carrying SMA may be due to the autosomal recessive mode of inheritance and the population carrier rate of approximately $1 / 50 .{ }^{26}$ Common to all four conditions are the reproductive options available to individuals who are aware of their carrier or gene positive status.

The frequency of predictive testing for HD determined in this audit contrasts with other studies that have documented the uptake of HD predictive testing in families. The higher proportion of testing reported from this audit may be a symptom of the inclusion and exclusion criteria. Tassicker et al. ${ }^{27}$ determined that $13 \%$ to $15 \%$ of family members who were at $50 \%$ risk of developing HD had predictive testing in the state of Victoria. In contrast, the uptake of predictive testing by family members at $50 \%$ risk of HD included in this study was $45 \%$. The inclusion criteria of this audit defined that probands had to be diagnosed within a 5 -year period between the years 2000 and 2004. The proband being the index case of HD in the family meant that, in contrast to the study conducted by Tassicker et al. ${ }^{27}$ these families had no known prior family history of HD and therefore potentially limited life experience or exposure to living with family members affected with HD. ${ }^{27}$ This lack of experience may reduce family members' inhibition toward testing, which contrasts with families with multiple 
generational experiences of family members developing and succumbing to $\mathrm{HD}$ and few choosing to have predictive testing. ${ }^{28}$

\section{Limitations}

The main limitation of this study is the inclusion in the calculation of the proportion of at-risk family members who had genetic testing of at-risk family members marked on pedigrees as a symbol without any identifying details. Therefore, the percentages presented in the findings are a minimum estimate of the proportion of tested at-risk family members. The absence of details about these nonidentifiable family members made it impossible to determine whether any had genetic testing by searching the laboratory reports. The pedigrees of families at risk of a chromosomal translocation and SMA contained more than $60 \%$ of family members lacking identifying details, whereas a third of family members at risk of carrying FXS or developing HD were nonidentifiable. There is also a possibility that another medical specialist, such as a general practitioner, may have ordered genetic testing for a chromosomal translocation or carrier testing for SMA or FXS for these individuals without referring them to GHSV or that relatives were out of state or overseas. Nevertheless, it is likely that if other medical specialists requested testing for these individuals, some would subsequently be referred to GHSV for counseling about the test and the implications. In addition, the laboratory report of the test result may be filed in the families' genetic files held at GHSV if the test referral indicates the proband's details. In contrast, it is a requirement of GHSV that $\mathrm{HD}$ predictive testing cannot be conducted without pretest counseling with the HD counselor; therefore, it is unlikely that family members at risk of HD who lack identifying details have had predictive testing for HD.

\section{Conclusion}

In conclusion, the uptake of genetic testing by at-risk family members varies according to condition and is likely to be influenced by a number of factors including family communication and the health and reproductive implications of the genetic condition. The communication of genetic information in families is likely to play an influential role in the uptake of genetic testing by at-risk family members, particularly those who are more closely related to the proband. Therefore, it is imperative that families are provided with support from genetic services while communicating to their family members to ensure that at-risk family members are optimally informed about their risk and are empowered to make informed decisions about genetic testing.

\section{ACKNOWLEDGMENTS}

The authors acknowledge Obioha Ukoumunne for his assistance with the statistical analysis. This work was supported by an Australian Research Council grant (DP 0556183) and by the Victorian Government's Operational Infrastructure Support Program. Martin Delatycki is funded through an NHMRC Practitioner Fellowship.

\section{DISCLOSURE}

The authors declared no conflict of interest.

\section{REFERENCES}

1. Forrest K, Simpson SA, Wilson BJ, et al. To tell or not to tell: barriers and facilitators in family communication about genetic risk. Clin Genet 2003;64:317-326.

2. Sermijn E, Goelen G, Teugels E, et al. The impact of proband mediated information dissemination in families with a BRCA1/2 gene mutation. J Med Genet 2004;41:e23

3. Andrew SE, Goldberg YP, Kremer B, et al. The relationship between trinucleotide (CAG) repeat length and clinical features of Huntington's disease. Nat Genet 1993;4:398-403.

4. Sobel SK, Cowan DB. Impact of genetic testing for Huntington disease on the family system. Am J Med Genet 2000;90:49-59.

5. Binedell J, Soldan JR, Harper PS. Predictive testing for Huntington's disease: II. Qualitative findings from a study of uptake in South Wales. Clin Genet 1998;54:489-496.

6. Binedell J, Soldan JR, Harper PS. Predictive testing for Huntington's disease: I. Predictors of uptake in South Wales. Clin Genet 1998;54:477-488.

7. Holloway SM, Bernhard B, Campbell H, Lam WW. Uptake of testing for BRCA1/2 mutations in South East Scotland. Eur J Hum Genet 2008;16:906-912.

8. Foster C, Evans DG, Eeles R, et al. Predictive testing for BRCA1/2: attributes, risk perception and management in a multi-centre clinical cohort. Br J Cancer 2002;86:1209-1216.

9. Hanley JA, Negassa A, Edwardes MD, Forrester JE. Statistical analysis of correlated data using generalized estimating equations: an orientation. Am J Epidemio/ 2003;157:364-375.

10. Goldstein H. Multilevel Statistical Models, 3rd edn. Arnold: London, 2003.

11. McClaren BJ, Metcalfe SA, Aitken M, Massie RJ, Ukoumunne OC, Amor DJ. Uptake of carrier testing in families after cystic fibrosis diagnosis through newborn screening. Eur J Hum Genet 2010;18:1084-1089.

12. Ormond KE, Mills PL, Lester LA, Ross LF. Effect of family history on disclosure patterns of cystic fibrosis carrier status. Am J Med Genet C Semin Med Genet 2003;119C:70-77.

13. van Rijn MA, de Vries BB, Tibben A, van den Ouweland AM, Halley DJ, Niermeijer MF. DNA testing for fragile $X$ syndrome: implications for parents and family. J Med Genet 1997;34:907-911.

14. Forrest LE, Burke J, Bacic S, Amor DJ. Increased genetic counseling support improves communication of genetic information in families. Genet Med 2008;10:167-172.

15. Suthers GK, Armstrong J, McCormack J, Trott D. Letting the family know: balancing ethics and effectiveness when notifying relatives about genetic testing for a familial disorder. J Med Genet 2006;43:665-670.

16. Richards M. Families, kinship and genetics. In: Marteau TM, Richards M (eds). The Troubled Helix: Social and Psychological Implications of the New Human Genetics. Cambridge University Press: Cambridge, 1996:249-273.

17. d'Agincourt-Canning L. Experiences of genetic risk: disclosure and the gendering of responsibility. Bioethics 2001;15:231-247.

18. McClaren BJ, Metcalfe SA, Aitken MA, Massie RJ, Ukoumunne OC, Amor DJ. Uptake of carrier testing in families after cystic fibrosis diagnosis through newborn screening. Eur J Hum Genet 2010;18:1084-1089.

19. Forrest LE, Delatycki MB, Curnow L, Skene L, Aitken M. Genetic health professionals and the communication of genetic information in families: practice during and after a genetic consultation. Am J Med Genet A 2010;152A:1458-1466.

20. Deftos LJ. Genomic torts: the law of the future - the duty of physicians to disclose the presence of a genetic disease to the relatives of their patients with the disease. Univ San Francisco Law Rev 1997;32:105-137.

21. Pate v. Threlkel. Wests South Report: Florida. Supreme Court, 1995:278-282.

22. Safer v. Estate of Pack. Atl Report: New Jersey. Superior Court, Appellate Division, 1996:1188-1193.

23. Papassotiropoulos A. Individualized medicine and pharmacogenomics. Nervenarzt 2007;78:468-469.

24. Wittenberger MD, Hagerman RJ, Sherman SL, et al. The FMR1 premutation and reproduction. Fertil Steril 2007;87:456-465.

25. Cusin V, Clermont O, Gérard B, Chantereau D, Elion J. Prevalence of SMN1 deletion and duplication in carrier and normal populations: implication for genetic counselling. J Med Genet 2003;40:e39.

26. Smith M, Calabro V, Chong B, Gardiner N, Cowie S, du Sart D. Population screening and cascade testing for carriers of SMA. Eur J Hum Genet 2007;15:759-766.

27. Tassicker RJ, Teltscher B, Trembath MK, et al. Problems assessing uptake of Huntington disease predictive testing and a proposed solution. Eur J Hum Genet 2009;17:66-70.

28. Trembath MK, Tassicker RJ, Collins VR, Mansie S, Sheffield LJ, Delatycki MB. Fifteen years of experience in predictive testing for Huntington disease at a single testing center in Victoria, Australia. Genet Med 2006;8:673-680. 